\title{
Penerapan Metode Fuzzy Tsukamoto untuk Pemilihan Karyawan Terbaik Berbasis Java Desktop
}

\author{
Fandra Satria ${ }^{1}$, Alexander J.P. Sibarani ${ }^{2}$ \\ ${ }^{1,2}$ Program Studi Teknik Informatika, Fakultas Teknologi Informasi, Universitas Budi Luhur \\ ${ }^{1,2} \mathrm{Jl}$. Ciledug Raya, Petukangan Utara, Jakarta Selatan, 12260, telp. (021) 5853753 \\ e-mail: ${ }^{1}$ fandra.satria.24@gmail.com, ${ }^{2}$ alexander.sibarani@budiluhur.ac.id
}

\begin{abstract}
Abstrak
Penelitian ini dilakukan di PT. Patra Trading, yang memiliki bisnis utama pada aktivitas niaga produk-produk non BBM. Perusahaan memandang bahwa kinerja pegawai perlu ditingkatkan melalui pemberian penghargaan secara periodik terhadap karyawan yang memiliki kinerja terbaik. Pemilihan karyawan berkinerja terbaik selama ini dilakukan dengan menerapkan tiga kriteria yaitu: Absensi, kepribadian, dan problem solving. Penilaian dilakukan dengan mengambil data dari mesin absensi dan pengamatan secara visual. Untuk kriteria kepribadian dan problem solving sering diabaikan karena nilai yang bersifat subjektif. Seluruh perhitungan dilakukan secara manual. Sistem pendukung keputusan perlu diterapkan untuk dapat mengatasi hal tersebut. Metode fuzzy tsukamoto merupakan metode yang digunakan untuk membantu dalam pemberian rekomendasi secara cepat, tepat, dan akurat. Maka dikembangkan sebuah aplikasi yang dapat memberi rekomendasi terhadap penentuan karyawan berkinerja terbaik berdasarkan kriteria yang sudah ditentukan. Dari hasil pengujian, seluruh fungsi berjalan dengan baik dan diperoleh hasil karyawan yang memperoleh nilai tertinggi dengan status "TERBAIK" memperoleh nilai probabilitas 90,85586.
\end{abstract}

Kata kunci: Fuzzy, Karyawan, Tsukamoto, Sistem Pendukung Keputusan

\begin{abstract}
This research was conducted at PT. Patra Trading, which has a main business in trading activities of non-fuel products. The company considers that employee performance needs to be improved through periodic rewards of employees who have the best performance. The selection of the best performing employees so far has been done by applying three criteria, namely: Attendance, personality, and problem solving. Assessment is done by taking data from the attendance machine and visual observation. For personality criteria and problem solving are often ignored because the values are subjective. All calculations are done manually. Decision support systems need to be implemented to overcome this. Tsukamoto fuzzy method is a method used to assist in providing recommendations quickly, precisely, and accurately. Then an application was developed that could provide recommendations for determining the best performing employees based on predetermined criteria. From the test results, all functions run well and the results obtained by employees who received the highest value with the status of "BEST" obtained a probability value of 90.8586.
\end{abstract}

Keywords: Fuzzy, Employee, Tsukamoto, Decision Support System

\section{Pendahuluan}

Dalam sebuah perusahaan, kualitas karyawan menjadi aspek penting dalam mendukung kemajuan perusahaan. Karyawan yang loyal dan memiliki kualitas dapat membantu perusahaan untuk tumbuh dan berkembang dengan pesat, untuk menentukan karyawan berkualitas 
diperlukan manajemen sumber daya manusia di sebuah perusahaan dengan melakukan pemilihan karyawan terbaik untuk meningkatkan semangat dan kinerja karyawan di perusahaan. Oleh karena itu digunakan Teknologi Informasi (TI) masa kini untuk mempermudah suatu pekerjaan. Salah satu manfaat TI yaitu dapat membantu dalam membuat keputusan dalam perusahaan.

PT. Patra Trading merupakan perusahaan yang memiliki bisnis utama di bidang perniagaan produk-produk non BBM. Selain itu perusahaan ini juga mengelola Depot, mengoperasikan Stasiun Pengisian Bulk Elpiji (SPBE), dan Terminal Aspal Curah. Direksi menganggap bahwa karyawan yang bekerja di perusahaannya adalah aset penting perusahaan sebagai roda penggerak bagi kelangsungan perusahaan. Untuk memacu karyawan agar dapat meningkatkan kontribusi positif di perusahaan, direksi secara rutin mengadakan pemilihan karyawan terbaik dalam lingkup internal perusahaan. Yang terjadi selama ini adalah proses perhitungan pemilihan karyawan terbaik dilakukan secara manual. Perhitungan manual saat ini tidak menggunakan tools apapun. Proses pemilihan karyawan terbaik yang dilakukan mempertimbangkan beberapa kriteria yaitu: absensi, kepribadian, dan problem solving. Untuk kriteria absensi, yang dihitung adalah presentasi kehadiran karyawan yang dikumpulkan setiap harinya. Proses yang dilakukan adalah mengambil data absensi dari mesin absensi dan pengamatan secara visual oleh pengawas. Sementara untuk kriteria kepribadian dan problem solving, kriteria ini sering diabaikan oleh atasan karena tidak adanya tools untuk menginput nilai karyawan sehingga sering tidak dimasukkan ke penilaian oleh atasan dari karyawan. Untuk menentukan hasil selanjutnya, dilakukan perhitungan secara manual dengan membandingkan kriteria yang ada di data karyawan tersebut. Masalah ini menyebabkan keputusan penilaian karyawan terbaik menjadi tidak standar.

Untuk memecahkan masalah tersebut maka diperlukan suatu proses perhitungan yang tepat, akurat, dan cepat sehingga proses pengambilan keputusan dapat segera dilakukan. Untuk memudahkan proses tersebut maka diperlukan sebuah sistem yang dapat mendukung pengambilan keputusan secara cepat dan akurat. Penentuan keputusan haruslah diambil berdasarkan kriteria yang sudah ditentukan dan harus diikuti bersama. Agar sistem ini dapat membantu dalam proses pengambilan keputusan, maka dibutuhkan sistem berbasis komputer yang fleksibel dan dapat diadaptasi, yang mampu mengolah data menjadi informasi dan dapat mendukung solusi, memberi rekomendasi, maupun mengevaluasi sebuah peluang [1].

Salah satu metode yang dapat diimplementasikan pada Sistem Pendukung Keputusan adalah metode Fuzzy Tsukamoto. Metode ini sudah banyak diterapkan untuk membantu dalam penarikan kesimpulan ataupun keputusan dalam berbagai bidang. Metode Fuzzy Tsukamoto merupakan metode penarikan kesimpulan setiap konsekuen pada aturan yang berbentuk IFTHEN harus direpresentasikan dengan suatu himpunan fuzzy dengan fungsi keanggotaan yang monoton. Sebagai hasilnya, output hasil inferensi dari tiap-tiap aturan diberikan dengan tegas (crips) berdasarkan $\alpha$-predikat (fire strength). Hasil akhirnya diperoleh dengan menggunakan rata-rata terbobot. Metode ini dipilih karena metode tsukamoto bersifat intuitif dan dapat memberikan rekomendasi dan nilai berdasarkan informasi yang masih belum akurat, ambigu, maupun bersifat kualitatif [2-5].

Berdasarkan latar belakang tersebut, maka diimplementasikan sebuah sistem pendukung keputusan dengan menerapkan metode Fuzzy Tsukamoto dalam penentuan karyawan terbaik di PT Patra Trading dnegan menetapkan tiga kriteria dalam proses pengambilan keputusan yaitu: nilai absensi, nilai kepribadian, dan nilai problem solving. Terdapat beberapa penelitian yang digunakan sebagai referensi dalam penyelesaian penelitian ini [6-11]. Seperti pada penelitian Erlangga dkk (2018), dimana tema penelitian adalah mengembangkan sistem pendukung keputusan terbaik untuk penerima bonus kinerja dosen terbaik menggunakan metode Tsukamoto dengan menggunakan 5 kriteria. Hasilnya sesuai dengan harapan dimana diperoleh daftar dosen 
yang berhak mendapatkan bonus [6]. Selain itu terdapat penelitian yang dilakukan oleh Ridwan Boki dkk. (2016) yang mengembangkan sistem pendukung keputusan penentuan guru berprestasi dengan menerapkan metode Fuzzy Tsukamoto di SMP Negeri 5 Kendari. Penelitian ini berusaha menetapkan kriteria-kriteria yang bersifat subjektif agar menjadi lebih objektif dan dapat diukur. Hasilnya penelitian ini dapat diterapkan untuk membantu memberi keputusan guru terbaik [7]. Terdapat juga penelitian lain di bidang produksi, dimana metode Fuzzy Tsukamoto dimanfaatkan untuk membantu menentukan jumlah produksi nanas di salah satu industri bidang pertanian. Hal ini berguna untuk keputusan penggunaan sumber daya lain di bidang produksi [8]. Selain penelitian di atas, terdapat beberapa penelitian lain yang digunakan sebagai acuan landasan teori untuk penelitian ini dalam menerapkan logika fuzzy [12-14]. Beberapa referensi ini digunakan sebagai pembanding dalam mengembangkan sistem pendukung keputusan khususnya perbandingan terhadap kriteria-kriteria yang masih bersifat kualitatif.

\section{Metode Penelitian}

\subsection{Metode Pembangunan Sistem}

Metode yang digunakan dalam penelitian ini mengacu pada metode pengembangan sistem Waterfall. Pengembangan sistem ini digambarkan melalui diagram alir penelitian di bawah ini.

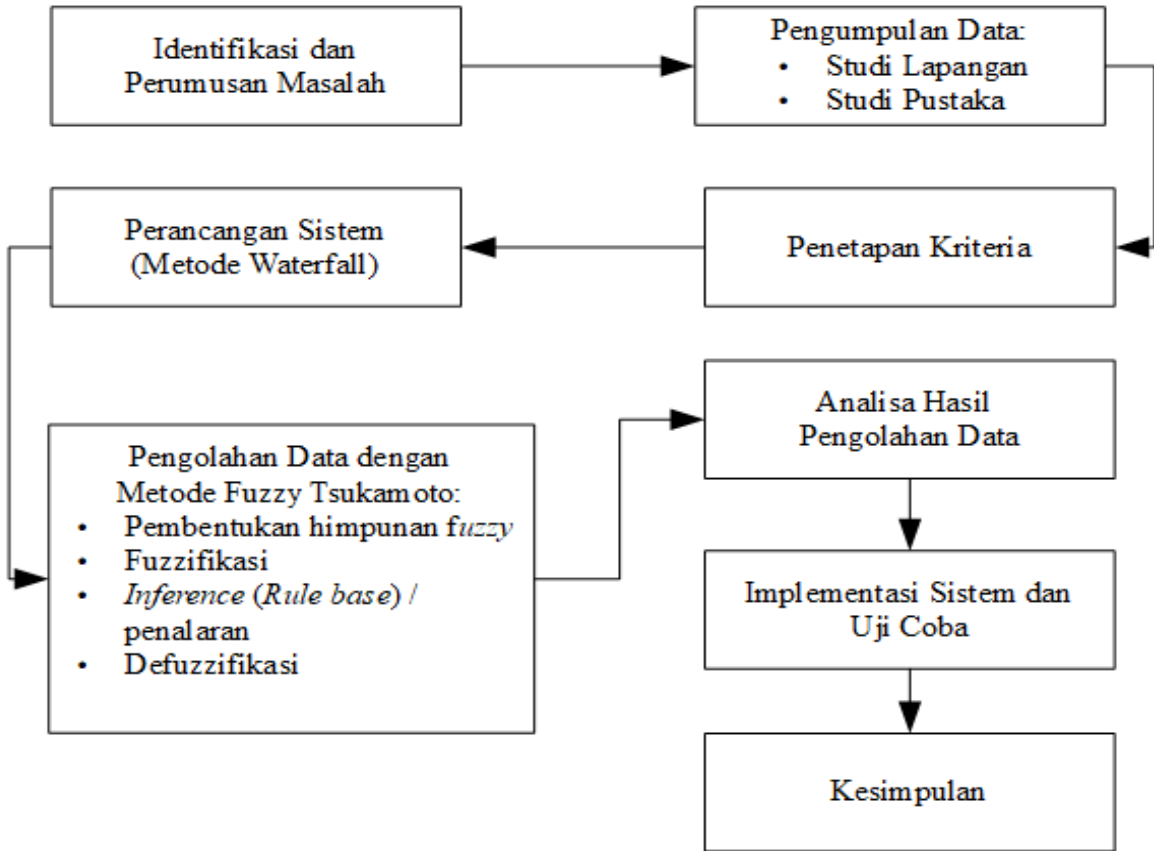

Gambar 4. Diagram Alur Penelitian

\subsection{Tahapan Metode Fuzzy Tsukamoto}

Terdapat empat tahapan yang dilalui dalam logika fuzzy, yaitu:

a. Pembentukan himpunan fuzzy

Himpunan fuzzy merupakan pembentukan rentang-rentang nilai berdasarkan variabel yang sudah ditentukan

b. Fuzzifikasi

Merupakan proses untuk mengubah variabel non fuzzy (variabel numerik) menjadi variabel fuzzy (variabel numerik)

c. Inferencing (Base Rule)

Proses pembentukan aturan-aturan fuzzy yang dinyatakan dalam bentuk "IF...THEN" 
d. Defuzzifikasi

Proses pengubahan kembali hasil keputusan yang masih dalam bentuk fuzzy menjadi variabel numerik non fuzzy

Pada penelitian ini, metode Fuzzy Tsukamoto menggunakan data absensi, kepribadian, dan problem solving sebagai variabel yang akan direpresentasikan dengan fungsi keanggotaan fuzzy. Selanjutnya akan ditentukan derajat keanggotaan keputusan untuk menentukan derajat nilai terbaik dan tidak terbaik.

\section{a. Derajat Keanggotan Absensi}

Derajat keanggotaan absensi memiliki 3 representasi himpunan fuzzy, yaitu fungsi derajat keanggotaan linier turun untuk representasi himpunan fuzzy disiplin, fungsi derajat keanggotaan linier naik untuk untuk himpunan fuzzy kurang disiplin, dan fungsi derajat keanggotaan segitiga untuk himpunan fuzzy cukup disiplin.

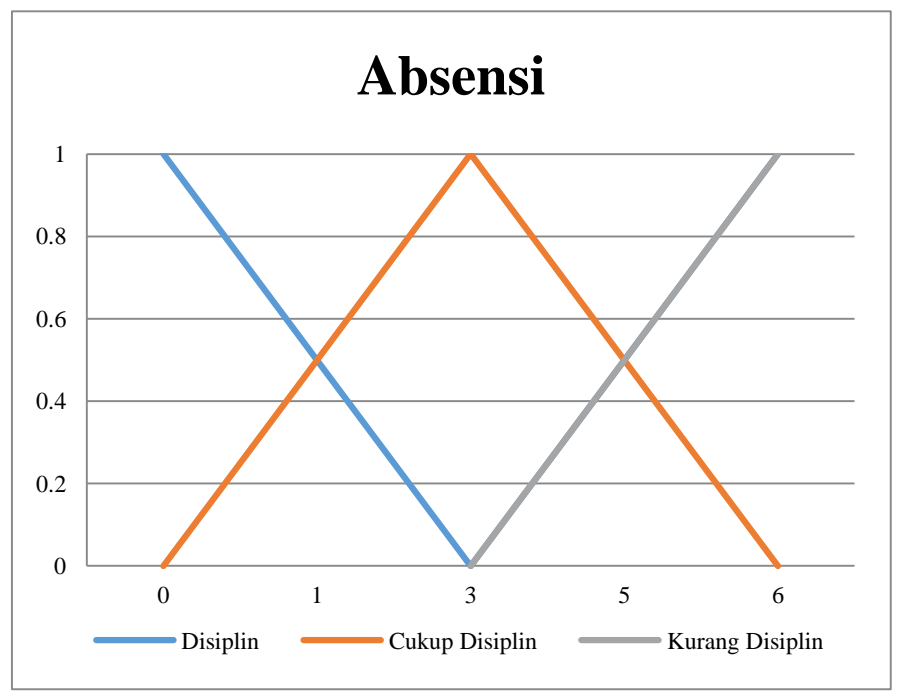

Gambar 4. Representasi Fungsi Derajat Keanggotaan Nilai Absensi

$1 \quad ; \mathrm{x}<0$

$$
\begin{array}{lcl}
\mu \text { Disiplin (x) } & (3-\mathrm{x}) / 3-0 & ; 0 \leq \mathrm{x} \leq 3 \\
0 & ; \mathrm{x}>3 \\
& (\mathrm{x}-0) / 3-0 & ; 0 \leq \mathrm{x} \leq 3 \\
\mu \text { Cukup Disiplin (x) } & (6-\mathrm{x}) / 6-3 & ; 3 \leq \mathrm{x} \leq 6 \\
& 0 & ; \mathrm{x}<0 \| \mathrm{x}>6 \\
\mu \text { Kurang Disiplin (x) } & (\mathrm{x}-3) / 6-3 & ; 3 \leq \mathrm{x} \leq 6 \\
& 1 & ; \mathrm{x}>6
\end{array}
$$

\section{b. Derajat Keanggotaan Kepribadian}

Derajat keanggotaan kepribadian memiliki 3 representasi himpunan fuzzy, yaitu fungsi derajat keanggotaan linier turun untuk representasi himpunan fuzzy kurang, fungsi derajat keanggotaan linier naik untuk untuk himpunan fuzzy baik, dan fungsi derajat keanggotaan segitiga untuk himpunan fuzzy cukup. 


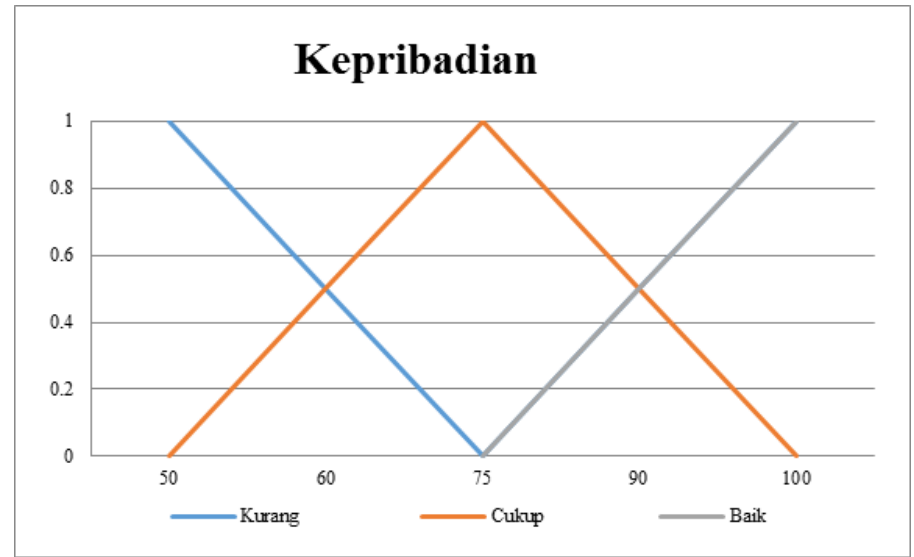

Gambar 5. Representasi Fungsi Derajat Keanggotaan Nilai Kepribadian

$$
1 \quad ; \mathrm{x}<50
$$

$\mu$ Kurang (x)

$(75-x) / 75-50 ; 50 \leq x \leq 75$

$0 \quad ; \mathrm{x}>75$

$(\mathrm{x}-50) / 75-50 ; 50 \leq \mathrm{x} \leq 75$

$\mu$ Cukup (x) $\quad(100-x) / 100-75 ; 75 \leq x \leq 100$

$0 \quad ; \mathrm{x}<50 \| \mathrm{x}>100$

$0 \quad ; \mathrm{x}<75$

$\mu \operatorname{Baik}(\mathrm{x}) \quad(\mathrm{x}-75) / 100-75 \quad ; 75 \leq \mathrm{x} \leq 100$

$1 \quad ; \mathrm{x}>100$

\section{c. Derajat Keanggotaan Problem Solving}

Derajat keanggotaan problem solving memiliki 3 representasi himpunan fuzzy, yaitu fungsi derajat keanggotaan linier turun untuk representasi himpunan fuzzy kurang, fungsi derajat keanggotaan linier naik untuk untuk himpunan fuzzy bagus, dan fungsi derajat keanggotaan segitiga untuk himpunan fuzzy cukup.

$$
1 \quad ; \mathrm{x}<50
$$

$\mu \operatorname{Kurang}(\mathrm{x}) \quad(75-\mathrm{x}) / 75-50 ; 50 \leq \mathrm{x} \leq 75$

$0 \quad ; \mathrm{x}>75$

$$
(\mathrm{x}-50) / 75-50 ; 50 \leq \mathrm{x} \leq 75
$$

$\mu$ Cukup (x) $\quad(100-\mathrm{x}) / 100-75 ; 75 \leq \mathrm{x} \leq 100$

$$
0 \quad ; \mathrm{x}<50 \| \mathrm{x}>100
$$

$0 \quad ; \mathrm{x}<75$

$\mu$ Bagus $(\mathrm{x}) \quad(\mathrm{x}-75) / 100-75 ; 75 \leq \mathrm{x} \leq 100$

$$
1 \quad ; \mathrm{x}>100
$$




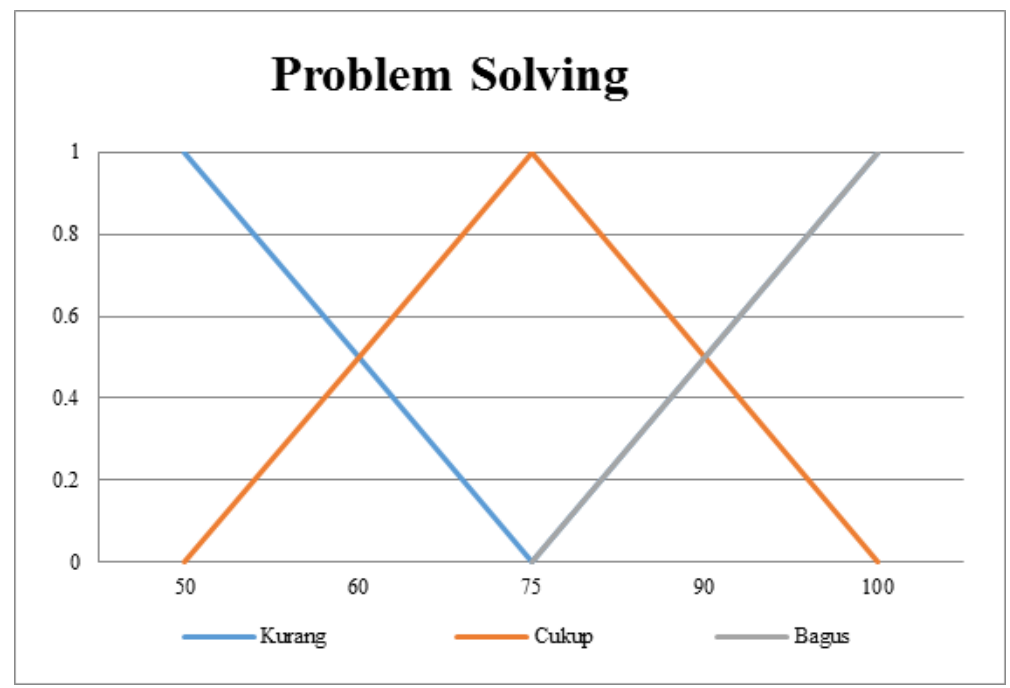

Gambar 6. Representasi Fungsi Derajat Keanggotaan Nilai Problem Solving

\section{d. Derajat Keanggotaan Keputusan}

Derajat keanggotaan keputusan memiliki 2 representasi himpunan fuzzy, yaitu fungsi derajat keanggotaan linier turun untuk representasi himpunan fuzzy tidak terbaik dan fungsi derajat keanggotaan linier naik untuk untuk himpunan fuzzy terbaik.

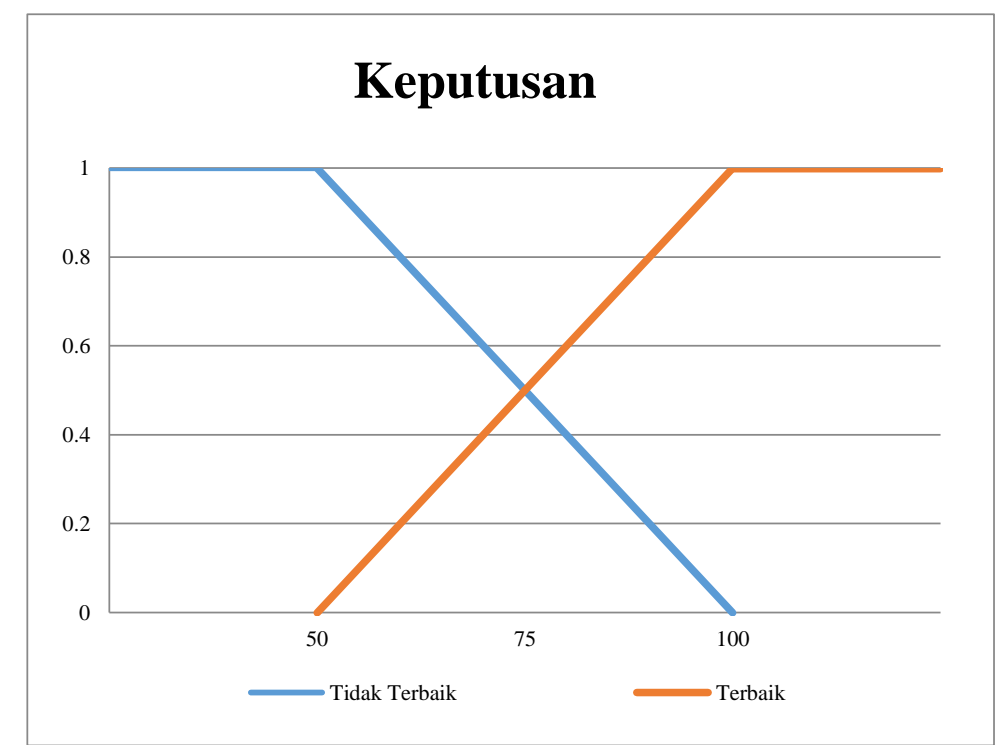

Gambar 7. Representasi Fungsi Derajat Keanggotaan Nilai Keputusan

$\mu$ Tidak Terbaik (z)

$1 ; \mathrm{z}<0$

$(100-\mathrm{z}) / 100-0 ; 0 \leq \mathrm{z} \leq 100$

$0 \quad ; z>100$

$0 \quad ; \mathrm{z}<50$

$\mu$ Terbaik (z)

$$
\begin{array}{cl}
(\mathrm{z}-50) / 100-50 & ; 50 \leq \mathrm{z} \leq 100 \\
1 & ; \mathrm{z}>100
\end{array}
$$




\section{e. Langkah-Langkah Penyelesaian}

Berikut ini penjelasan mengenai langkah-langkah penyelesaian masalah menggunakan fuzzy dengan sebuah kasus.

Seorang pengawas mengajukan form data penilaian kinerja karyawan bernama Suhartono kepada admin dengan ketentuan sebagai berikut:
Absensi : :0
Kepribadian $: 82$
Problem Solving : 81

Karena nilai absensi termasuk dalam keanggotaan disiplin dan cukup disiplin, nilai kepribadian termasuk dalam keanggotaan cukup dan baik, dan problem solving termasuk dalam keanggotaan cukup dan bagus, maka dilakukan proses pengambilan keputusan untuk selanjutnya menentukan predikat karyawan tersebut apakah termasuk dalam kategori terbaik atau tidak terbaik. Untuk mendapatkan keputusan yang tepat proses selanjutnya dilakukan dengan metode fuzzy tsukamoto.

a. Fuzzifikasi

Langkah pertama adalah mencari keanggotaan masing-masing variabel input yang digunakan.

\section{Absensi}

Jika nilai absensi $=0$ maka derajat keanggotaan fuzzy pada setiap himpunan adalah:

(1) Himpunan fuzzy disiplin $\quad=1$

(2) Himpunan fuzzy cukup disiplin $\quad=0$

(3) Himpunan fuzzy kurang disiplin $\quad=0$

Kepribadian

Jika nilai kepribadian $=82$ maka derajat keanggotaan fuzzy pada setiap himpunan adalah:
(1) Himpunan fuzzy kurang
$=0$
(2) Himpunan fuzzy cukup
$=0,72$
(3) Himpunan fuzzy baik
$=0,28$

\section{Problem Solving}

Jika nilai problem solving $=81$ maka derajat keanggotaan fuzzy pada setiap himpunan adalah:

(1) Himpunan fuzzy kurang $\quad=0$

(2) Himpunan fuzzy cukup $\quad=0,76$

(3) Himpunan fuzzy bagus $=0,24$

\section{b. Pembentukan Rule}

Langkah kedua adalah menentukan rule yang berbentuk IF-THEN dari himpunan fuzzy yang telah dibuat.

Tabel 1. Tabel Rule Setiap Himpunan Fuzzy

\begin{tabular}{|c|c|c|c|}
\hline C1 & C2 & C3 & Keputusan \\
\hline Disiplin & Baik & Bagus & Terbaik \\
\hline Disiplin & Baik & Cukup & Terbaik \\
\hline Disiplin & Baik & Kurang & Tidak Terbaik \\
\hline Disiplin & Cukup & Bagus & Terbaik \\
\hline
\end{tabular}

eISSN: 2477-3255, pISSN: 2086-4884

https://doi.org/10.31849/digitalzone.v11i1.3944 


\begin{tabular}{|c|c|c|c|}
\hline Disiplin & Cukup & Cukup & Terbaik \\
\hline Disiplin & Cukup & Kurang & Tidak Terbaik \\
\hline Disiplin & Kurang & Bagus & Tidak Terbaik \\
\hline Disiplin & Kurang & Cukup & Tidak Terbaik \\
\hline Disiplin & Kurang & Kurang & Tidak Terbaik \\
\hline Cukup Disiplin & Baik & Bagus & Terbaik \\
\hline Cukup Disiplin & Baik & Cukup & Terbaik \\
\hline Cukup Disiplin & Baik & Kurang & Tidak Terbaik \\
\hline Cukup Disiplin & Cukup & Bagus & Terbaik \\
\hline Cukup Disiplin & Cukup & Cukup & Terbaik \\
\hline Cukup Disiplin & Cukup & Kurang & Tidak Terbaik \\
\hline Cukup Disiplin & Kurang & Bagus & Tidak Terbaik \\
\hline Cukup Disiplin & Kurang & Cukup & Tidak Terbaik \\
\hline Cukup Disiplin & Kurang & Kurang & Tidak Terbaik \\
\hline Kurang Disiplin & Baik & Bagus & Tidak Terbaik \\
\hline Kurang Disiplin & Baik & Cukup & Tidak Terbaik \\
\hline Kurang Disiplin & Baik & Kurang & Tidak Terbaik \\
\hline Kurang Disiplin & Cukup & Bagus & Tidak Terbaik \\
\hline Kurang Disiplin & Cukup & Cukup & Tidak Terbaik \\
\hline Kurang Disiplin & Cukup & Kurang & Tidak Terbaik \\
\hline Kurang Disiplin & Kurang & Bagus & Tidak Terbaik \\
\hline Kurang Disiplin & Kurang & Cukup & Tidak Terbaik \\
\hline Kurang Disiplin & Kurang & Kurang & Tidak Terbaik \\
\hline
\end{tabular}

Keterangan:

C1: Absensi

C2: Kepribadian

C3: Problem Solving

c. Mesin Inferensi

Langkah selanjutnya adalah penerapan fungsi implikasi MIN untuk mendapatkan nilai $\alpha$ terkecil dari nilai himpunan fuzzy yang ada di setiap rule. Kemudian mencari nilai z dari setiap rule dengan rumus $\mathbf{z i}=\mathbf{z m a x i} \boldsymbol{- \alpha i}(\mathbf{z m a x i}-\mathbf{z m i n i})$. 
Tabel 2. Fungsi Implikasi MIN Setiap Rule dan nilai z Setiap Rule

\begin{tabular}{|c|c|c|c|c|c|}
\hline $\mathrm{C} 1$ & $\mathrm{C} 2$ & $\mathrm{C} 3$ & Keputusan & $\alpha \mathrm{i}$ & zi \\
\hline 1 & 0,28 & 0,24 & Terbaik & 0,24 & 94 \\
\hline 1 & 0,28 & 0,76 & Terbaik & 0,28 & 93 \\
\hline 1 & 0,28 & 0 & Tidak Terbaik & 0 & 75 \\
\hline 1 & 0,72 & 0,24 & Terbaik & 0,24 & 94 \\
\hline 1 & 0,72 & 0,76 & Terbaik & 0,72 & 82 \\
\hline 1 & 0,72 & 0 & Tidak Terbaik & 0 & 75 \\
\hline 1 & 0 & 0,24 & Tidak Terbaik & 0 & 75 \\
\hline 1 & 0 & 0,76 & Tidak Terbaik & 0 & 75 \\
\hline 1 & 0 & 0 & Tidak Terbaik & 0 & 75 \\
\hline 0 & 0,28 & 0,24 & Terbaik & 0 & 100 \\
\hline 0 & 0,28 & 0,76 & Terbaik & 0 & 100 \\
\hline 0 & 0,28 & 0 & Tidak Terbaik & 0 & 75 \\
\hline 0 & 0,72 & 0,24 & Terbaik & 0 & 100 \\
\hline 0 & 0,72 & 0,76 & Terbaik & 0 & 100 \\
\hline 0 & 0,72 & 0 & Tidak Terbaik & 0 & 75 \\
\hline 0 & 0 & 0,24 & Tidak Terbaik & 0 & 75 \\
\hline 0 & 0 & 0,76 & Tidak Terbaik & 0 & 75 \\
\hline 0 & 0 & 0 & Tidak Terbaik & 0 & 75 \\
\hline 0 & 0,28 & 0,24 & Tidak Terbaik & 0 & 75 \\
\hline 0 & 0,28 & 0,76 & Tidak Terbaik & 0 & 75 \\
\hline 0 & 0,28 & 0 & Tidak Terbaik & 0 & 75 \\
\hline 0 & 0,72 & 0,24 & Tidak Terbaik & 0 & 75 \\
\hline 0 & 0,72 & 0,76 & Tidak Terbaik & 0 & 75 \\
\hline 0 & 0,72 & 0 & Tidak Terbaik & 0 & 75 \\
\hline 0 & 0 & 0,24 & Tidak Terbaik & 0 & 75 \\
\hline 0 & 0 & 0,76 & Tidak Terbaik & 0 & 75 \\
\hline 0 & 0 & 0 & Tidak Terbaik & 0 & 75 \\
\hline
\end{tabular}


Keterangan:

C1: Absensi

C2: Kepribadian

C3: Problem Solving

d. Defuzzifikasi

Langkah selanjutnya adalah defuzzifikasi output fuzzy. Proses defuzzifikasi pada metode tsukamoto menggunakan metode Weight yaitu dengan membagi jumlah dari hasil $\alpha^{*} \mathrm{z}$ yang ada disetiap rule dengan jumlah dari $\alpha$ yang ada di setiap rule.

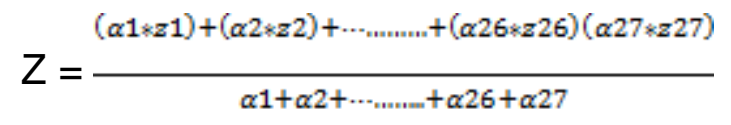

$=87,972973$

Setelah mendapatkan nilai $\mathrm{Z}$ langkah yang selanjutnya adalah mencari keanggotaan masing-masing dari variabel output lalu membandingkannya.

Pemilihan Karyawan Terbaik

Jika nilai $\mathrm{Z}=87,972973$ maka derajat keanggotaan fuzzy pada setiap himpunan adalah:

(1) Himpunan fuzzy Tidak Terbaik $=0.12027$

(2) Himpunan fuzzy Terbaik $\quad=0.75946$

Dari hasil perbandingan nilai himpunan output diatas himpunan fuzzy terbaik lebih besar dibandingkan himpunan fuzzy tidak terbaik. Himpunan fuzzy terbaik mempunyai nilai himpunan 0.75946 sedangkan himpunan fuzzy tidak terbaik mempunyai nilai himpunan 0.12027. Jadi, keputusan yang diambil adalah karyawan dengan nama Suhartono menjadi karyawan terbaik.

\section{Hasil dan Pembahasan}

\subsection{Tampilan layar Aplikasi}

Berikut ini merupakan tampilan dari layar aplikasi yang telah dikembangkan dalam penelitian ini.

a. Tampilan Layar Form Login

Merupakan layar autentikasi untuk dapat masuk ke dalam aplikasi.

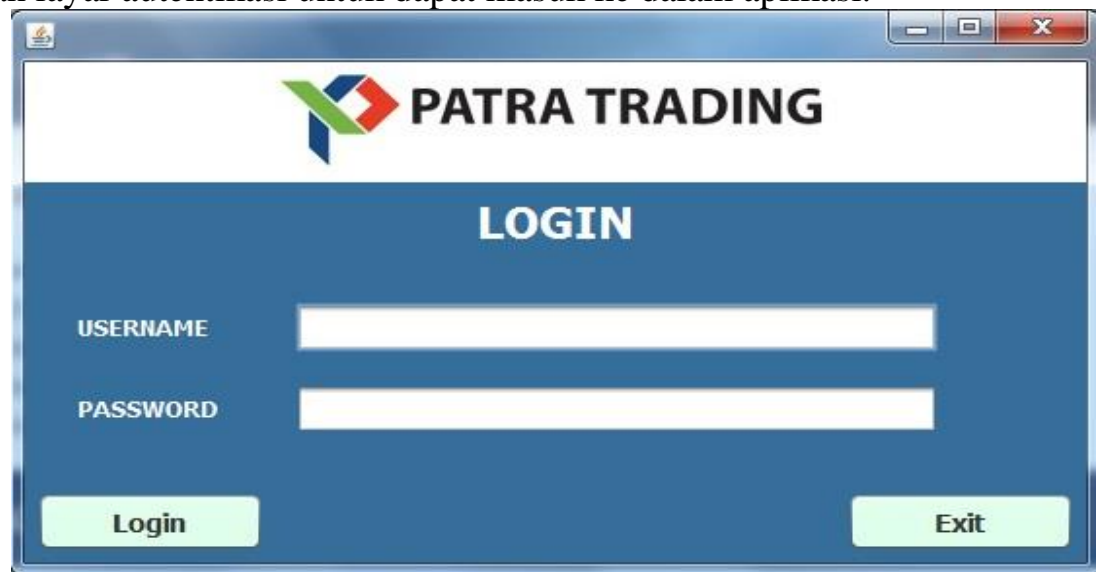

Gambar 8. Tampilan Layar Form Login

b. Tampilan Layar Form Data Karyawan

Form data karyawan berfungsi untuk menambah, menyimpan, mengubah, dan menghapus data karyawan. 


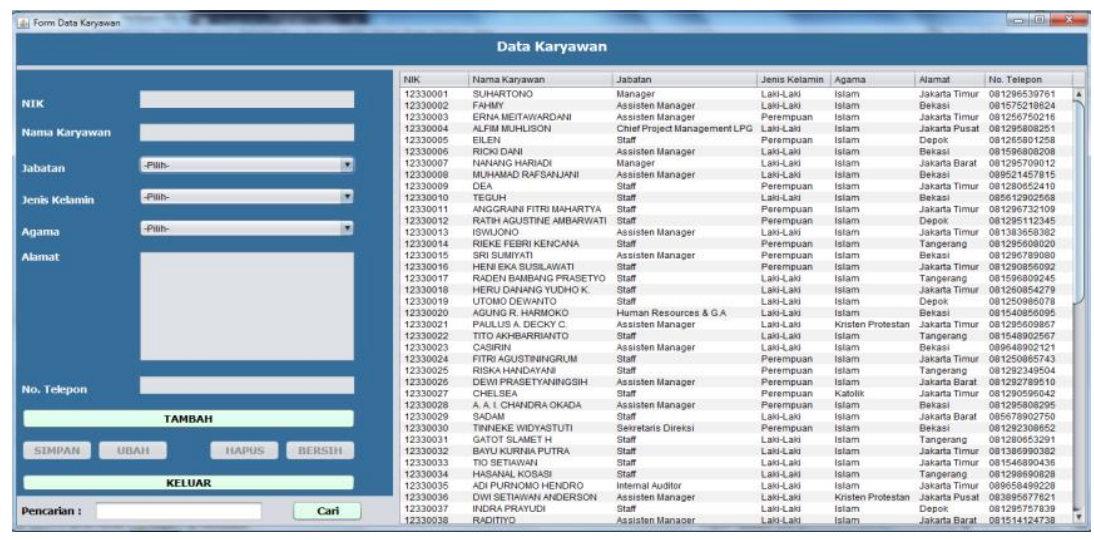

Gambar 9. Tampilan Layar Form Data Karyawan

c. Tampilan Layar Form Data Penilaian

Form data penilaian berfungsi untuk menambah, menyimpan, mengubah, dan menghapus data nilai karyawan.

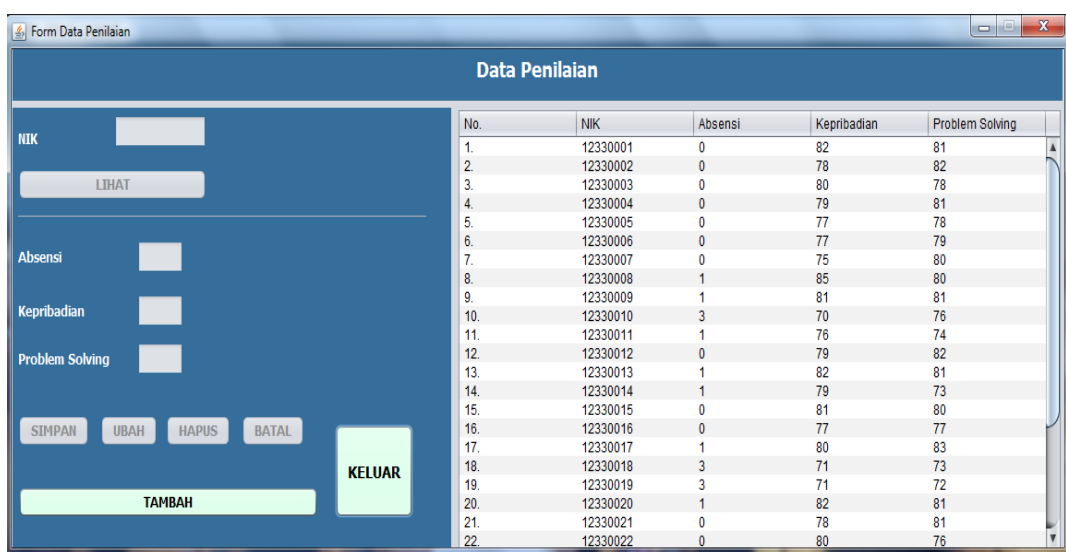

Gambar 10. Tampilan Layar Form Data Penilaian

d. Tampilan Layar Proses Pemilihan Karyawan Terbaik

Tampilan proses pemilihan karyawan terbaik berfungsi untuk memilih karyawan terbaik yang ditentukan dengan 3 kriteria yaitu absensi, kepribadian dan problem solving. Kemudian diproses dengan fuzzy logic dengan metode tsukamoto.

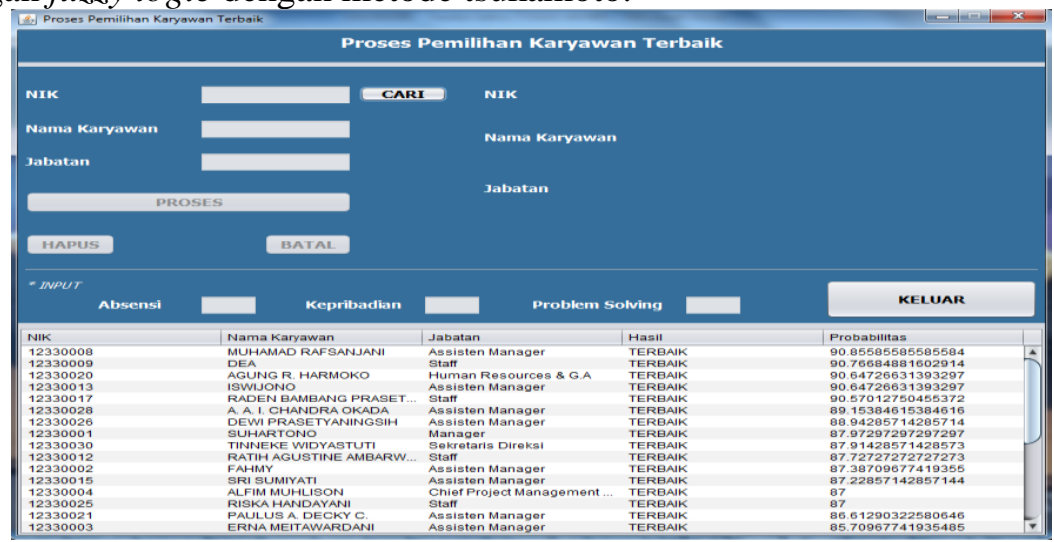

Gambar 11. Tampilan Layar Proses Pemilihan Karyawan Terbaik 
Lalu setelah menekan tombol proses akan muncul pesan hasil karyawan tersebut terbaik atau tidak dan ada nilai probabilitasnya.

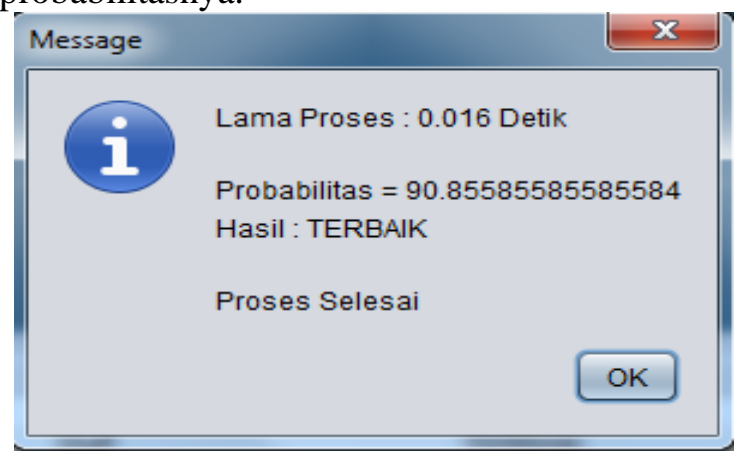

Gambar 12. Pesan Dari Proses Pemilihan Karyawan Terbaik

e. Tampilan Layar Laporan Data Karyawan Terbaik

Laporan data karyawan terbaik berfungsi untuk melihat atau mencetak data karyawan terbaik yang sudah diproses dan tersimpan di database

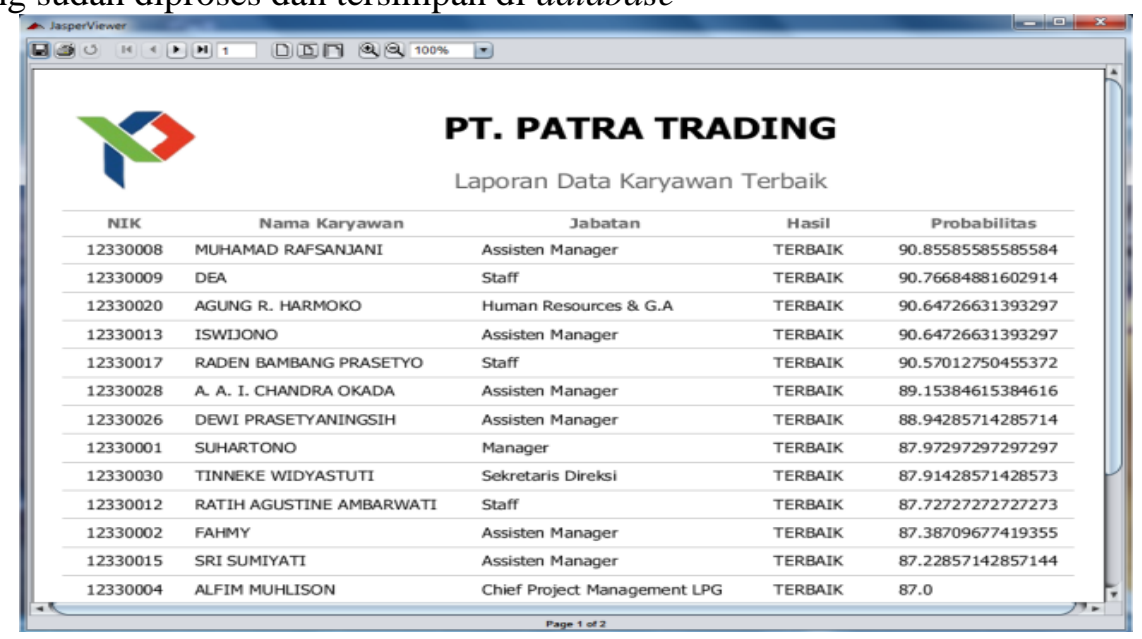

Gambar 13. Tampilan Layar Laporan Data Karyawan Terbaik

\subsection{Pengujian Aplikasi}

Pengujian terhadap aplikasi dilakukan dengan cara menguji coba proses pemilihan karyawan berkinerja terbaik dengan membandingkan nilai dari 3 kriteria yang sudah ditentukan

Tabel 3. Tabel Uji Coba

\begin{tabular}{|c|c|c|c|c|c|}
\hline NIK & Nama & Jabatan & C1 & C2 & C3 \\
\hline 12330001 & Suhaxxxxx & Manager & 0 & 82 & 81 \\
\hline 12330002 & Fahmx & Asst. Man. & 0 & 78 & 82 \\
\hline 12330003 & Ernaxx & Asst. Man. & 0 & 80 & 78 \\
\hline 12330004 & Alfixxx & CPM LPG & 0 & 79 & 81 \\
\hline 12330005 & Eilex & Staff & 0 & 77 & 78 \\
\hline 12330006 & Rickixx & Asst. Man. & 0 & 77 & 79 \\
\hline 12330007 & Nanaxxxx & Manager & 0 & 75 & 80 \\
\hline 12330008 & M. Raxxxxxxxx & Asst. Man. & 1 & 85 & 80 \\
\hline 12330009 & Dea & Staff & 1 & 81 & 81 \\
\hline 12330010 & Tegux & Staff & 4 & 70 & 70 \\
\hline
\end{tabular}



Keterangan:
C1: Absensi
C2: Kepribadian
C3: Problem Solving

Table 4. Tabel Hasil Pengujian

\begin{tabular}{|c|c|c|c|c|}
\hline NIK & Nama & Jabatan & Hasil & Probabilitas \\
\hline 12330001 & Suhaxxxxx & Manager & TERBAIK & 87,97297 \\
\hline 12330002 & Fahmx & Asst. Man. & TERBAIK & 87,38710 \\
\hline 12330003 & Ernaxx & Asst. Man. & TERBAIK & 85,70968 \\
\hline 12330004 & Alfixxx & CPM LPG & TERBAIK & 87,0 \\
\hline 12330005 & Eilex & Staff & TERBAIK & 82,72414 \\
\hline 12330006 & Rickixx & Asst. Man. & TERBAIK & 83,96552 \\
\hline 12330007 & Nanaxxxx & Manager & TERBAIK & 83,0 \\
\hline 12330008 & M. Raxxxxxxxx & Asst. Man. & TERBAIK & 90,85586 \\
\hline 12330009 & Dea & Staff & TERBAIK & 90,76685 \\
\hline 12330010 & Tegux & Staff & TIDAK TERBAIK & 65,55556 \\
\hline
\end{tabular}

Berdasarkan hasil diatas, menunjukkan bahwa menurut perhitungan fuzzy tsukamoto dengan kriteria nilai absensi, kepribadian dan problem solving yang telah dimasukkan, maka yang menjadi karyawan "TERBAIK" dengan nilai probabilitas tertinggi adalah atas nama M. Raxxxxxxxx dengan nilai probabilitas 90,85586. Berdasarkan tabel diatas jika diurutkan berdasarkan probabilitas yang tertinggi maka urutannya adalah: 1) M. Raxxxxxxxx, 2) Dea, 3) Suhaxxxxx, 4) Fahmx, 5) Alfixxx, 6) Erna xx, 7) Rickixx, 8) Nanaxxxx, 9) Eilex, 10) Tegux.

\section{Kesimpulan}

Berdasarkan hasil analis dan perancangan sistem pemilihan karyawan terbaik dengan metode fuzzy tsukamoto, maka dapat diambil kesimpulan bahwa fuzzy dapat digunakan dalam pemilihan karyawan terbaik berdasarkan data karyawan dengan menggunakan 3 kriteria yaitu: absensi, kepribadian dan problem solving. Hasil dari perhitungan tergantung kepada absensi, kepribadian dan problem solving serta rule yang dipakai dalam fuzzy. Hasil Perhitungan dapat digunakan sebagai rekomendasi untuk membantu perusahaan dalam penentuan karyawan berkinerja terbaik. Untuk penelitian selanjutnya dapat menggunakan metode yang berbeda dalam perhitungan menentukan karyawan berkinerja terbaik dan membandingkan tingkat efisiensi dari tiap metode.

\section{Daftar Pustaka}

[1] Kusrini. Konsep dan Aplikasi Sistem Penunjang Keputusan. Yogyakarta: Andi. 2007.

[2] Mulyanto, A., Haris, A. Penerapan Metode Fuzzy Tsukamoto Untuk Menentukan Jumlah Jam Overtime Pada Produksi Barang di PT. Asahi Best Base Indonesia (ABBI) Bekasi. Jurnal Informatika SIMANTIK. 2016; 1(1): 1-11.

[3] Rohayani, H. Fuzzy Inference System Dengan Metode Tsukamoto Sebagai Penunjang Keputusan Produksi (Studi Kasus: PT. Talkindo Selaksa Anugrah). JSI: Jurnal Sistem Informasi (E-Journal). 2015; 7(1): 753-764.

[4] Amalia, Y., Rijal, Y. Sistem Pendukung Keputusan Penetapan Tunjangan Prestasi Dengan Menggunakan Metode Fuzzy-Tsukamoto (Studi Kasus Di PT. Boxtime Indonesia). Jurnal Matematika "MANTIK". 2016; 1(2): 17-25. 
[5] Nugraha, E., Wibawa, A., Hakim, M., Kholifah, U., Dini, R., Irwanto, M. Implementation of Fuzzy Tsukamoto Method in Decision Support System of Journal Acceptance. Journal of Physics: Conference Series. Bandung. 2019; 1280: 1-6.

[6] Erlangga, Dharmawan, Y.Y. Penentuan Penerima Kinerja Dosen Award Melalui Metode Tsukamoto Dengan Konsep Logika Fuzzy. Explore - Jurnal Sistem Informasi dan Telematika. 2018; 9(2): 152-161.

[7] Boki, R., Statiswaty, Subardin. Sistem Pendukung Keputusan Penentuan Calon Guru Berprestasi Menggunakan Metode Fuzzy Tsukamoto "Studi Kasus: SMP Negeri 5 Kendari”. Jurnal SemanTIK. 2016; 2(2): 93-102.

[8] Prayogi, A., Santoso, E., Sutrisno. Sistem Pendukung Keputusan Untuk Penentuan Jumlah Produksi Nanas Menggunakan Metode Fuzzy Tsukamoto (Studi kasus PT.Great Giant Pineapple). Jurnal Pengembangan Teknologi Informasi dan Ilmu Komputer. 2018; 2(6): 2032-2037.

[9] Dharma, S.A., Pattiasina, T.J., Trianto, E.M. Perancangan Aplikasi Rekomendasi Pemilihan Lokasi Rumah dengan Memanfaatkan Fuzzy Database Metode Tahani. Jurnal TEKNIKA. 2015; 4(1): 23-28.

[10] Yulia, Mardiah, A. Fuzzy Logic Untuk Menentukan Kepuasan Siswa Terhadap Sarana dan Prasarana Sekolah Dengan Menggunakan Metode Sugeno. Jurnal Ilmiah Informatika (JIF). 2018; 6(1): 32-41.

[11] Saepullah, A., Wahono, R.S. Comparative Analysis of Mamdani, Sugeno And Tsukamoto Method of Fuzzy Inference System for Air Conditioner Energy Saving. Journal of Intelligent Systems. 2015; 1(2): 143-147

[12] Susilo, F. Himpunan dan Logika Kabur Serta Aplikasinya. Yogyakarta: Graha Ilmu. 2006.

[13] Sutojo, T., Mulyanto, E., Suhartono, V. Kecerdasan Buatan. Yogyakarta: Andi Offset. 2011.

[14] Kusumadewi, S., Purnomo, H. Aplikasi Logika Fuzzy Untuk Pendukung Keputusan. Yogyakarta: Graha Ilmu. 2010.

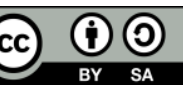

Digital Zone: Jurnal Teknologi Informasi dan Komunikasi is licensed under a Creative Commons Attribution International (CC BY-SA 4.0) 